\title{
Design equations for reinforced concrete members strengthened in shear with external FRP reinforcement formulated in an evolutionary multi-objective framework
}

\author{
Ricardo Perera Antonio Ruiz
}

\begin{abstract}
A B S T R A C T
Methods for predicting the shear capacity of FRP shear strengthened RC beams assume the traditional approach of superimposing the contribution of the FRP reinforcing to the contributions from the reinforcing steel and the concrete. These methods become the basis for most guides for the design of externally bonded FRP systems for strengthening concrete structures. The variations among them come from the way they account for the effect of basic shear design parameters on shear capacity. This paper presents a simple method for defining improved equations to calculate the shear capacity of reinforced concrete beams externally shear strengthened with FRP. For the first time, the equations are obtained in a multiobjective optimization framework solved by using genetic algorithms, resulting from considering simultaneously the experimental results of beams with and without FRP external reinforcement. The performance of the new proposed equations is compared to the predictions with some of the current shear design guidelines for strengthening concrete structures using FRPs. The proposed procedure is also reformulated as a constrained optimization problem to provide more conservative shear predictions.
\end{abstract}

\section{Introduction}

Strengthening methods based on plate bonding with fiber-reinforced polymers (FRPs) are gaining acceptance all over the world to retrofit concrete structures [1,2]. Nowadays, one of the major applications of FRP composites for strengthening reinforced concrete (RC) members is their use as additional web reinforcement to increase the shear capacity of the members. However, unlike methods for flexural strengthening, shear strengthening with externally bonded FRP laminates has not been addressed to the same extent [3-8].

Current shear design procedures assume that the nominal shear strength of an FRP externally strengthened concrete member can be determined by adding the contribution of the FRP reinforcing to the contributions from the reinforcing steel (stirrups, ties or spirals) and the concrete. The concrete contribution includes the dowel action from longitudinal steel reinforcement and is determined by empirically found relationships. In the standard design method, similar to the current US design practices, the concrete contribution is calculated for members without web reinforcement. The contribution from steel stirrups is calculated by using the truss theory and, as with concrete contribution, is evaluated according to the current building code. Different truss models for FRP plate bonding have been proposed to evaluate the FRP contribution $[5,7,9-12,4]$.

However, despite the substantial amount of experimental and numerical work on this subject, accurately calculating the shear capacity of FRP shear strengthened RC beams remains a complex challenge that has not yet been fully resolved, as highlighted in the different design guidelines [13-17] proposed until now.

The objective of this paper is to develop simple yet accurate shear design equations for FRP shear strengthened RC beams by dealing with the problem from a different point of view. The proposed equations have been developed by using an optimization approach. To do this, experimental shear capacity results of a series of reinforced concrete beams and FRP shear strengthened reinforced concrete beams have been taken as a reference. The optimization approach is developed in a multiobjective framework by considering RC beams with and without FRP external reinforcement. Evolutionary algorithms, such as genetic algorithms (GAs), are especially suitable for solving multiobjective problems when compared to standard optimization methods [18]. Furthermore, GAs are conceptually simple, easy to implement and yield accurate results when solving optimization problems, as has been demonstrated through their application to other kinds of problems such as design optimization problems $[19,20]$ or structural identification $[21,22]$. 
The key features of the proposed procedure are outlined and examples are provided for evaluating the validity of the method by comparison with some current codes of practice and results from experimental tests.

\section{Current shear design equations}

The truss model, also known as the strut and tie model, has become the basis for many concrete codes such as Eurocode 2 [23], the ACI code [24] and the Spanish EHE [25]. This model assumes that after cracking of the concrete, the behavior of a reinforced concrete beam becomes analogous to that of a truss with a top longitudinal compression cord, a bottom longitudinal tension cord, vertical steel ties and diagonal concrete struts. This model assumes that only the steel stirrups carry the tensile forces. In the standard design method, similar to the current US design practices and other codes, a concrete contribution without web reinforcement is added to the shear capacity.

When the model is applied to FRP shear strengthened RC beams, in all existing design proposals, the design shear strength, $V_{R d}$ is evaluated from

$V_{R d}=V_{c}+V_{s}+V_{f}$

where $V_{c}$ is the contribution of concrete, $V_{s}$ is the contribution of the steel stirrups and $V_{f}$ is the contribution of the FRP.

The shear strength of the concrete $V_{c}$ for a cracked section depends on the dowel action of the longitudinal reinforcement, the diagonal tensile strength of the uncracked part of the concrete and the aggregate interlocking effect; $V_{c}$ may be calculated according to the provisions in existing $\mathrm{RC}$ design codes using the expressions for shear strength provided by concrete without web reinforcement which are based on empirical data.

One of the easiest ways to determine the concrete contribution is based on the dimensions of the member, $b$ and $d$, and the compressive strength of the concrete, $f_{c}^{\prime}$ :

$V_{c}=b d\left(f_{c}^{\prime}\right)^{1 / n}$

where $n$ is usually equal to 2 or 3 depending on the code chosen.

The contribution from steel stirrups can be expressed by using the truss theory as follows:

$V_{s}=\left(A_{s} / S\right) f_{y} z \cot \theta$

where $A_{s}=$ area of the transverse stirrups at spacing $s, f_{y}=$ yield strength of the shear reinforcement, $z$ is the flexural lever arm and $\theta$ is the local inclination of the compression strut.

By using truss analysis the contribution from the FRP can described as

$V_{f}=z \varepsilon_{f d} E_{f} \frac{A_{f}}{S_{f}} \sin \alpha_{f}\left(\cot \alpha_{f}+\cot \theta\right)$

where $E_{f}, A_{f}$ and $s_{f}$ are the elastic modulus and the area and the spacing of the FRP reinforcement, respectively, $\alpha_{f}$ is the angle for FRP reinforcement fiber direction in relation to the beam's longitudinal direction and $\varepsilon_{f d}$ is the critical strain design value of the transversal FRP reinforcement. Besides angle $\theta$, one of the key elements for predicting shear capacity in Eq. (4) is the calculation of an effective FRP strain.

\section{Multiobjective shear design problem}

The proposed approach to obtain shear design equations is developed as an optimization problem to define in a combined way equations for the shear design of RC beams with or without FRP external shear reinforcement and whose objective will be to minimize the difference between the measured shear strength of reinforced concrete beams with and without FRP external reinforcement and its calculated values. To this end, original forms of the expressions defining $V_{c}, V_{s}$ and $V_{f}$ such as defined in the previous section should be taken as the starting point. The equations should be the simplest and most accurate possible and should consider the main basic design parameters on the shear strength.

Taking as reference Eq. (2), the original form of the equation for the concrete contribution has been considered as follows:

$V_{c}=\frac{C_{1}\left(f_{c}^{\prime}\right)^{C_{3}} b d}{(a / d)^{C_{2}}}$

where $C_{1}, C_{2}$ and $C_{3}$ are unknown coefficients to be determined. Although not considered in the design equations, the shear span/ depth ratio has been included since as some studies have demonstrated $[7,26]$ it has a high influence on the shear capacity. Other effects, such as the longitudinal steel reinforcement ratio, have not been included; it has been assumed, such as postulated in some codes that failure shear strength does not increase if this ratio is higher than a threshold and, therefore, a simplified procedure has been adopted. In any case, the inclusion of the longitudinal steel reinforcement ratio is not problematic in the proposed procedure since it requires only the inclusion of a new term, and therefore a new parameter.

By analogy with Eq. (3), for the steel stirrups the following expression has been adopted

$V_{s}=C_{4}\left(A_{s} / S\right) f_{y} z \cot \left(C_{5} 45\right)$

where $C_{4}$ and $C_{5}$ are unknown coefficients to be determined. The form of this equation is well accepted and is similar in the different design equations, the main difference among them being in the choice of the crack inclination, $\theta$. For this reason, a coefficient, $C_{5}$, has been included to consider this aspect.

In addition, the original form of the equation giving the contribution of the FRP to the shear capacity has been considered as follows:

$V_{f}=C_{6} E_{f} d b \sin \alpha_{f}\left(\cot \alpha_{f}+\cot \left(C_{5} 45\right)\right) \varepsilon_{f d}\left(\frac{t_{f} w_{f}}{s_{f} b}\right)^{C_{7}}$

where $C_{6}$ and $C_{7}$ are unknown coefficients and $d$ is the depth of the effective beam section. Using experimental observations as a basis, a constant has been included to adjust more suitably the dependence on the ratio $\rho_{f}=\left(t_{f} w_{f} / s_{f} b\right)$. Furthermore, two different equations should be considered for $V_{f}$ depending on if full-wrapped or U-wrapped strips are used for the shear strengthening; although it is true that some design guidelines neglect the difference, test results demonstrate that is incorrect to treat the two configurations, U-wrapping and full wrapping, as the same.

The main objective of our design problem is to search for an optimum set of coefficients, $C_{1}$ to $C_{7}$, within the solution space in the above shear equations, for which the difference between the measured shear strength and that calculated using the final form of the optimized equations is minimal. To perform this, the problem will be developed in a multiobjective framework by simultaneously optimizing the equation to predict the shear capacity of reinforced concrete beams without FRP external shear reinforcement and the equation to predict the shear capacity of FRP shear strengthened reinforced concrete beams. In both cases, the objective functions will be constructed as a measure of how well the model's predicted output agrees with the experimentally measured data and have an expression as follows:

$F_{1}=V_{\text {expRC }}-V_{\text {predRC }}=V_{\text {expRC }}-\left(V_{c}+V_{s}\right)_{\text {pred }}$

$F_{2}=V_{\text {expRC+FRP }}-V_{\text {predRC+FRP }}=V_{\text {expRC+FRP }}-\left(V_{c}+V_{s}+V_{f}\right)_{\text {pred }}$ 
where $V_{\text {expRC }}$ and $V_{\text {predRC }}$ are the measured and the model-predicted shear capacities, respectively, in the case of beams without FRP external reinforcement, and $V_{\text {expRC+FRP }}$ and $V_{\text {predRC+FRP }}$ represent the same when FRP external reinforcement is added.

\subsection{Formulation of the multiobjective shear design problem}

The solution of a multiobjective problem like that posed in the previous section requires finding the values of the parameters $\left(C_{1}\right.$ to $C_{7}$ ) that simultaneously minimize the objectives

$F(\{C\})=\left(F_{1}(\{C\}), F_{2}(\{C\})\right)$

where $\{C\}=\left(C_{1}, C_{2}, C_{3}, C_{4}, C_{5}, C_{6}, C_{7}\right)$ is the vector grouping the coefficients which define the shear equations.

In multiobjective problems a set of solutions representing the trade-offs between the different objectives is sought rather than a unique optimal solution. The set of trade-off solutions is constituted by all the non-dominated solutions and is known as the Pareto optimal set or Pareto-optimal front. The non-dominated solutions are optimal in the sense that no other solutions in the search space are superior to them when all objectives are considered. No objective function can be improved from a Pareto optimal point without detriment to another objective function. The goal of multiobjetive optimization is to find the global Pareto optimal set.

For solving the multiobjective optimization problem, GAs have been adopted [27]. The main motivation for using GAs to solve this problem is because GAs deal simultaneously with a population of possible solutions which allows finding several members of the Pareto-optimal set in a single run of the algorithm, instead of having to perform a series of separate runs, as in the case of conventional mathematical-programming techniques. Because of this, GAs were used in this study to solve the optimization problem.

Among the different proposed evolutionary algorithms well suited to solving the multiobjective optimization problem based on the concept of Pareto optimality, the Strength Pareto Genetic Algorithm (SPGA) [28] has been used. The SPGA belongs to a second generation of multiobjective evolutionary algorithms born with the introduction of the notion of elitism. In the context of multiobjective optimization, elitism usually refers to the use of an external population to retain the non-dominated individuals found at each generation. For each individual in this external set, fitness is defined through a strength value based on Pareto dominance. This strength is proportional to the number of solutions which a certain individual dominates. For an individual of the non-external set (i.e., the population), its fitness is calculated by adding " 1 " to the total sum of the strengths of all the external members that dominate it. With this mechanism, population diversity is maintained without any explicit sharing. Additionally, the SPGA also incorporates a clustering procedure in order to keep the size of the external set while maintaining its characteristics.

\section{Experimental database}

To solve the optimization problem, two different databases were considered. The first collects the experimental results of 40 $\mathrm{RC}$ beams without FRP external reinforcement. The database, included in [29], and found mainly from tests results compiled by Cladera [30] and Bhatt and Kader [31], includes test results of simply supported RC beams subjected mostly to a concentrated load at the midspan at various shear span-to-depth ratios, strengths of concrete and steel, steel ratios and geometrical sizes with the purpose of evaluating the method when applied to a different range of values. All the specimens failed in shear.

The second database includes the experimental results of $89 \mathrm{RC}$ beams externally shear strengthened with FRP using U-jacketing and full wrapping configurations, 49 beams strengthened by FRP $\mathrm{U}$-jacketing and 40 beams strengthened by wrapping. The shear strength results were collected from published literature [12,3234]; all the specimens used in this work were collected such as grouped in [35]. Furthermore, the selected tests present a high diversity regarding the beam geometric ratios, reinforcement ratios, material properties and, therefore, failure loads. The beam parameters available from the experimental database are the load configuration, the geometry of the beam, the mechanical properties and configuration of concrete and internal reinforcement, and the geometry, configuration and mechanical properties of the external reinforcement. Only rectangular, simply supported beams were considered.

\section{Results}

As commented above, multiobjective GAs will provide equations capable of estimating the shear strength values of FRP shear strengthened RC beams as closely as possible to the experimentally measured ones. In all the studies performed in this study, the following parameters were chosen for the application of the proposed multiobjective genetic algorithm: (a) size of population =100; (b) crossover probability $=0.6$; (c) mutation probability $=0.03$; (d) maximum number of generations $=200$. These values are typical in GAs and were chosen after some previous numerical tests. Each parameter, $C_{1}$ to $C_{7}$, has been coded into a 4 -bit binary number and, then, the seven parameters have been translated into a chromosome of 28 bits length. A higher number of bits involves more precision in order to estimate the parameters. Once the optimal chromosome has been found, the parameter values are obtained through the inverse of the decoded values. The GA search space has been limited for each parameter separately by observing those equations provided by commonly used shear design standards and recommendations and after carrying out some previous numerical tests. The following range of values has been considered for each parameter: $C_{1}=[0,1] ; \quad C_{2}=[0,1] ; \quad C_{3}=[0.1,1] ; \quad C_{4}=[0,2] ;$ $C_{5}=[0.5,1.3] ; C_{6}=[0,2] ; C_{7}=[0.5,2]$.

Taking into account the stochastic nature of GAs, 25 independent runs were performed per GA and test problem in order to decrease the influence of random effects.

As commented previously, one of the key elements for predicting shear capacity is the calculation of an effective FRP strain. For this reason, to apply Eq. (7), the estimation of the FRP effective strain of the experimental beams used in the proposed multiobjective algorithm has been calculated with four design proposals, those proposed by the International Federation for Structural Concrete (FIB14) [13], the American Concrete Institute (ACI440) [14], the Concrete Society in the UK (TR55) [15] and the Italian National Research Council (CNR200) [16]. These proposals are summarized in Table 1. Therefore, four different predictions were obtained with the proposed approach. The values of the constants $\left(C_{1}\right.$ to $\left.C_{7}\right)$ for each one of the predictions are shown in Table 2. As was expected, the parameter more sensitive to the design proposal considered to evaluate the FRP effective strain is $C_{6}$ since, as observed in Eq. (7), it affects $\varepsilon_{f d}$ directly and there is a high disparity in the criteria used for its calculation. Furthermore, a considerable increase is observed in its value when full wrapping configuration is observed, especially when ACI440, TR55 and CNR200 are used, since the FRP contribution is higher in this case. According to the values obtained for $C_{6}$, design guides underestimate the values of $\varepsilon_{f d}$ for full wrapping and overestimate them for U-wrapping. The values of the parameter $C_{7}$ show the linear increase of the FRP contribution with the ratio $\rho_{f}$, especially when a fully wrapped configuration is carried out. These results show the importance of considering differentiated approaches for both configurations. Another interesting aspect to 
Table 1

FRP shear capacity and effective design strain according to different design guidelines.

\begin{tabular}{|c|c|c|c|c|c|}
\hline $\begin{array}{l}\text { Design } \\
\text { guide }\end{array}$ & General expression & $\mathrm{U}$ & W & $\begin{array}{l}\text { Continuous } \\
\text { Discontinuous }\end{array}$ & Comments \\
\hline FIB14 & $V_{f}=0.9_{\varepsilon_{f d}} E_{f} \rho_{f} b_{w} d\left(\cot \theta+\cot \alpha_{f}\right) \sin \alpha_{f}$ & $\varepsilon_{f, e}=\min \left\{\begin{array}{l}0.65\left(\frac{\left(\frac{f_{c m}^{2 / 3}}{E_{f} \rho_{f}}\right)^{0.56} \times 10^{-3}}{0.17\left(\frac{\left(\frac{f}{c / 3}\right.}{E_{f} \rho_{f}}\right)^{0.30} \varepsilon_{f u}}\right.\end{array}\right.$ & $\varepsilon_{f, e}=0.17\left(\frac{f_{c m}^{2 / 3}}{E_{f} \rho_{f}}\right)^{0.30} \varepsilon_{f u}$ & $\rho_{f}=2 t_{f} \sin \theta / b_{w}$ & $k=0.8$ \\
\hline & $\varepsilon_{f d}=\varepsilon_{f k} \quad \varepsilon_{f k}=k_{f, e}$ & & & $\rho_{f}=2\left(\frac{t_{f}}{b_{w}}\right)\left(\frac{w_{f}}{s_{f}}\right)$ & $E_{f}$ in $\mathrm{GPa}$ \\
\hline CNR200 & $V_{f}=\frac{1}{\gamma_{R} d} 0.9 d f_{f d} 2 t_{f}\left(\cot \theta+\cot \alpha_{f}\right) \frac{w_{f}}{p_{f}}$ & $f_{f d}=f_{f d d}\left(1-\frac{1}{3} \frac{l_{l} \sin \beta}{\min \left(0.9 d, h_{w}\right)}\right)$ & $\begin{array}{c}f_{f d}=f_{f d d}\left(1-\frac{1}{6} \frac{l_{2} \sin \beta}{\min \left(0.9 d, h_{w}\right)}\right)+ \\
+\frac{1}{2}\left(\Phi_{R} f_{f d}-f_{f d d}\right)\left(1-\frac{l_{\sin } \beta}{\min \left(0.9 d, h_{w)}\right)}\right)\end{array}$ & $\begin{array}{l}\text { Only introduces } \\
\text { differences if FRP } \\
\text { sheets' layout is } \\
\text { lateral }\end{array}$ & $\begin{array}{l}\Phi_{R}=0.2+1.6 \frac{r_{c}}{b_{w}} \\
0 \leqslant r_{c} / b_{w} \leqslant 0.5\end{array}$ \\
\hline TR55 & $V_{f}=E_{f} \varepsilon_{f d} A_{f \mathrm{f}} \frac{\left(d_{f}-\frac{n}{3} l_{t, \mathrm{max}}\right)}{s_{f}}\left(\sin \alpha_{f}+\cos \alpha_{f}\right)$ & $\begin{array}{l}\varepsilon_{f d}=\min \left(\varepsilon_{f d, u} / 2,0.64 \sqrt{\frac{f_{c t m}}{\varepsilon_{f} t_{j}}}, 0.004\right) \\
n=1\end{array}$ & $\begin{array}{l}\varepsilon_{f d}=\min \left(\varepsilon_{f d, u} / 2,0.64 \sqrt{\frac{f_{c t r m}}{E_{f d} t_{f}}}, 0.004\right) \\
n=0\end{array}$ & $\begin{array}{l}w_{f}=\sin \alpha_{f} \\
s_{f}=1 \\
-\end{array}$ & $l_{t, \max }=0.7 \sqrt{\sqrt{E_{f} t_{f}}}$ \\
\hline $\mathrm{ACl} 440$ & $V_{f}=\frac{2 n t_{f} w_{f} E_{f} f_{f d}\left(\cos \alpha_{f}+\sin \alpha_{f}\right) d_{f}}{s_{f}}$ & $\begin{array}{l}\varepsilon_{f d}=k_{v} \varepsilon_{f u} \leqslant 0.004 \quad \kappa_{v}=\frac{k_{1} k_{2} L_{e}}{11900 \varepsilon_{f u}} \\
k_{1}=\left(\frac{f_{c m}}{27}\right)^{2 / 3} \\
k_{2}=\frac{d_{f}-L_{p}}{d_{f}} \quad L_{e}=\frac{23300}{\left(n_{f} t_{f} E_{f}\right)^{0.58}}\end{array}$ & $\varepsilon_{f d}=0.004$ & $\begin{array}{l}s_{f}=\frac{w_{f}}{\sin \beta} \\
-\end{array}$ & $\begin{array}{l}V_{s}+V_{f} \leqslant 8 b_{w} d \sqrt{f_{c m}} \\
s_{f}^{\max }=\frac{d_{f}}{4}+w_{f}\end{array}$ \\
\hline
\end{tabular}

Table 2

Parameter values for the proposed equations.

\begin{tabular}{lccccccc}
\hline & $\mathrm{C}_{1}$ & $\mathrm{C}_{2}$ & $\mathrm{C}_{3}$ & $\mathrm{C}_{4}$ & $\mathrm{C}_{5}$ & $\mathrm{C}_{6}$ & $\mathrm{C}_{7}$ \\
\hline U-wrapping & & & & & & & \\
Fib 14 & 0.78 & 0.65 & 0.78 & 1.14 & 0.84 & 0.62 & 0.89 \\
CNR-DT & 0.83 & 0.59 & 0.76 & 1.17 & 0.82 & 0.56 & 0.90 \\
TR55 & 0.82 & 0.70 & 0.79 & 1.10 & 0.84 & 0.47 & 0.88 \\
ACl 440.2R-02 & 0.72 & 0.67 & 0.79 & 1.21 & 0.87 & 0.68 & 0.90 \\
W-wrapping & & & & & & & \\
Fib 14 & 0.70 & 0.20 & 0.75 & 1.38 & 0.96 & 1.16 & 0.99 \\
CNR-DT & 0.63 & 0.12 & 0.75 & 1.09 & 0.86 & 1.35 & 0.96 \\
TR55 & 0.61 & 0.25 & 0.78 & 1.04 & 0.92 & 1.76 & 0.99 \\
ACl 440.2R-02 & 0.67 & 0.34 & 0.78 & 1.09 & 0.92 & 1.40 & 1 \\
\hline & & & & & & &
\end{tabular}

comment from Table 2 concerns the parameters, $C_{1}, C_{2}$ and $C_{3}$, included in the evaluation of concrete contribution (Eq. (5)). As expected, the predictions for these parameters do not vary appreciably according to the proposal chosen to estimate $\varepsilon_{f d}$ and depend mainly on the type of configuration of the external reinforcement. $C_{3}$ values are very similar for both types of configuration and $C_{1}$ values are slightly higher when the $U$ configuration is chosen although the differences are low. The main differences are related to the $C_{2}$ parameter which affects the a/d ratio; $C_{2}$ values show a higher influence of this ratio on $V_{c}$ for the $W$ configuration. These results demonstrate the importance of considering the concrete contribution in the proposed model and, secondly, the importance of the equation chosen to predict $V_{c}$ when computing the total shear resistance implementing the model.

The performance of the shear equation optimized using the GA model for FRP shear strengthened reinforced concrete beams using $\mathrm{U}$-jacketing and full wrapping configurations is illustrated in Figs. 1 and 2, respectively, for both experimental data familiar and unfamiliar to the model. These last, not included in the development of the model, were used as validation set and include ten $\mathrm{U}$ - and seven $\mathrm{W}$-jacketing beams. The predictions lie above or below the target line, i.e., the line where the predicted value is equal to the experimental value. The nearer the points gather around the diagonal line, the better the predicted values. From a comparison point of view, the linear regression slope and the linear correlation coefficient for both strengthening configurations and for the four design proposals are shown in Table 3 . The figures and Table 3

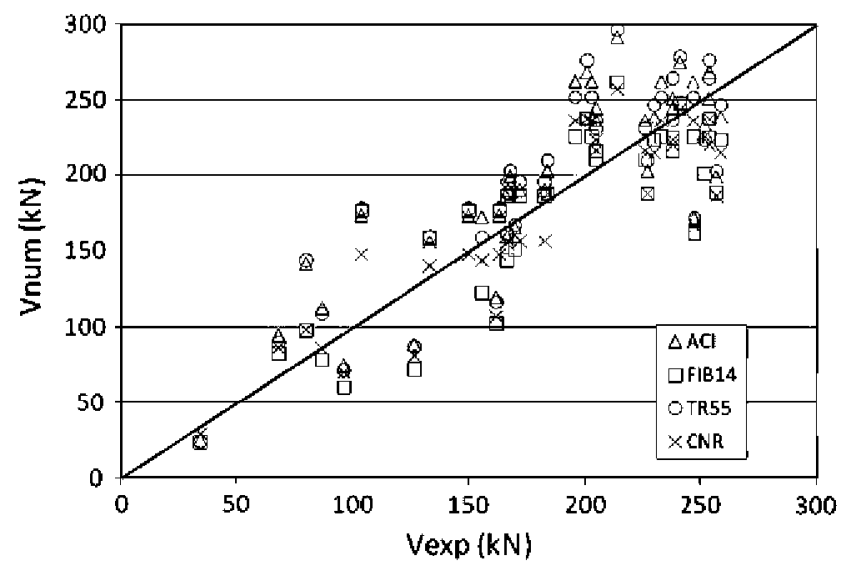

Fig. 1a. Comparison of shear strength obtained by the proposed equations for Uwrapped configuration - Familiar data.



Fig. 1b. Comparison of shear strength obtained by the proposed equations for Uwrapped configuration - Unfamiliar data. 


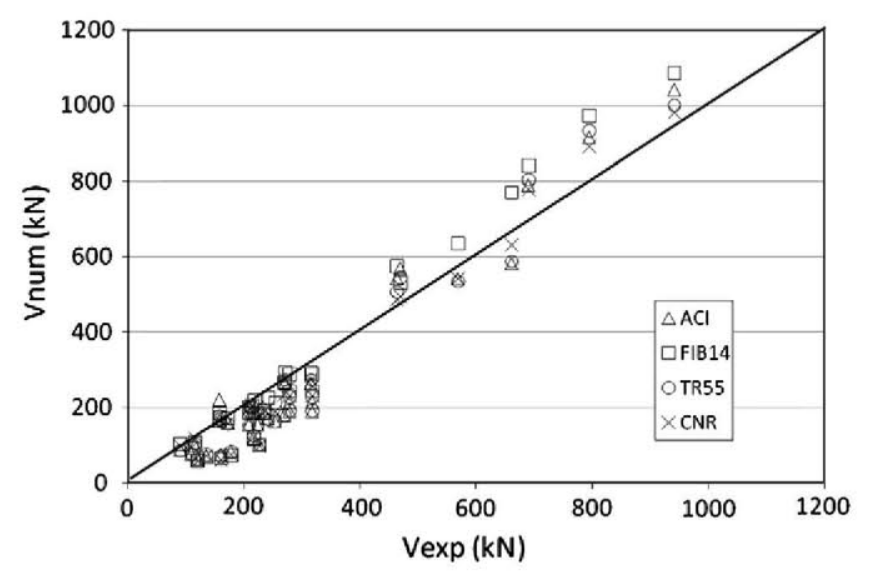

Fig. 2a. Comparison of shear strength obtained by the proposed equations for fully wrapped configuration - Familiar data.

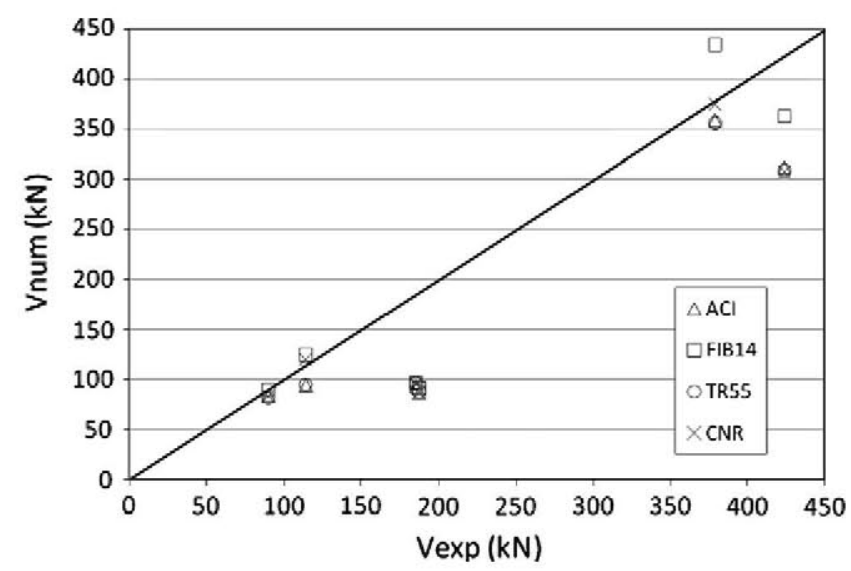

Fig. 2b. Comparison of shear strength obtained by the proposed equations for fully wrapped configuration - Unfamiliar data.

show, in general, for the proposed equations an overprediction of the shear capacity for full-wrapped configuration and an underprediction in the case of $U$-jacketing. A higher correlation is obtained for W-wrapping which is due to a lower sparsity in the experimental dataset. Evidently, the more the amount of experimental data used to evaluate the unknown parameters in the proposed multiobjective procedure, the better the predicted valued fits the proposed equations.

The statistical performance of the proposed model is shown in Table 4 on the whole of the experimental data for U-wrapping and full wrapping validation configurations. These predictions have been compared with those "theoretical" predictions provided by suitably combining some commonly used concrete codes and FRP design recommendations. Specifically, theoretical predictions given by EC2 [36] + FIB14, EC2 + CNR200, BS8110 [37] + TR55 and ACI318 $[24]+$ ACI440 have been included. The comparison is based on the average standard deviation (SD) and coefficient of variation (COV) of the ratio $V_{\text {exp }} / V_{\text {pred. }}$. With the same purpose, Table 4 also shows the average absolute error (AAE) calculated for $n$ specimens as

$A A E=\frac{1}{n} \sum_{i=1}^{n} \frac{\left|V_{\text {exp }}-V_{\text {pred }}\right|}{V_{\text {exp }}} 100$

for the total set of data and for the validation data.

In general terms, it is clear that, statistically, the predictions with the proposed procedure are very good and considerably improve the 'theoretical' predictions carried out with the different design guidelines, both $U$ and $W$ configurations. Furthermore, 'theoretical' predictions are considerably worse when carried out for full wrapping in comparison with U-wrapping.

Figs. 3 and 4 show the performance for all beams in the database for both configurations, respectively, by using the ratio of measured to calculated shear strength, $V_{\text {exp }} / V_{\text {pred. }}$. In both figures, theoretical predictions with the different design guides and with the proposed approach are shown and confirm what is commented above.

Taking into account that the problem was formulated in a multiobjective framework, predictions of shear capacities for RC beams without FRP external reinforcement were also obtained. In all the cases considered the average of the ratio $V_{\text {exp }} / V_{\text {pred }}$ for all the dataset was close to one.

\section{Conservative equations}

As observed above, with the proposed model, the predicted shear capacities for some specimens turn out to be higher than the experimental results. Should a reasonably more conservative result be preferred, the optimization problem might be reformulated as a constrained optimization problem. The constraints to which it should be subjected are:

$g_{i}=\max \left[0 ; \frac{V_{\text {predRC }+F R P}-V_{\text {expRC }+F R P}}{V_{\text {expRC }+F R P}}\right] \leqslant 0 \quad i=1,2, \ldots, m$

where $m$ is the number of specimens used to obtain the model.

\subsection{Reformulation of the problem}

The constraints are incorporated into the optimization problem through the inclusion of a penalty in the objective function $F_{2}$ (see Eq. (9)). The value of the penalty is dependent on the amount of each constraint violation present in a certain solution.

There are many penalty functions schemes proposed for structural design. In this study, a multiplicative form of the objective function proposed by Gen and Cheng [38] has been used as follows:

$F_{2}^{\prime}=F_{2}\left[1+\frac{1}{m} \sum_{i=1}^{m} G_{i}\right]=F_{2} \cdot P$

where $F_{2}^{\prime}=$ penalized objective function, $m=$ total number of constraints and $G_{i}=$ adaptive functions of the constraints $g_{i}$ defined as:

$G_{i}=\left(\frac{\Delta b_{i}}{b_{i}(t)}\right)^{k}$

where $\Delta b_{i}$ refers to the degree of violation of constraint $i$ and is defined as:

$\Delta b_{i}=\max \left[0, g_{i}-b_{i}(t)\right]$

and where $b_{i}(t)=$ penalty threshold for the $i$-th constraint, which is increasingly restrictive when the number of generation $t$ of the GA progresses and is defined by the form:

$b_{i}(t)=\frac{b_{i, 0}}{1+t}$

where $b_{i, 0}=$ penalty threshold for the $i$-th constraint used in the first generation of the GA. Therefore, the penalty is dynamically modified according to the present number of generation of the GA. The penalty threshold determines the value over which the constraint is considered active in the penalty factor $P$.

The exponent $k$ in Eq. (14) is a constant which adjusts the severity of the penalty. Values of 1 or 2 are usually proposed. 
Table 3

Linear regression slopes and coefficients of correlation of all the predictions performed.

\begin{tabular}{|c|c|c|c|c|c|c|c|c|}
\hline & \multicolumn{4}{|c|}{ Familiar data set } & \multicolumn{4}{|c|}{ Unfamiliar data set } \\
\hline & Fib 14 & CNR-DT & TR55 & ACI $440.2 \mathrm{R}-02$ & Fib 14 & CNR-DT & TR55 & $\mathrm{ACl} 440.2 \mathrm{R}-02$ \\
\hline Linear regression slope (U-wrapping) & 0.82 & 0.85 & 0.91 & 0.89 & 0.84 & 0.88 & 1.04 & 0.98 \\
\hline Linear correlation coefficient (U-wrapping) & 0.84 & 0.87 & 0.84 & 0.84 & 0.84 & 0.90 & 0.86 & 0.86 \\
\hline Linear regression slope (W-wrapping) & 1.29 & 1.13 & 1.17 & 1.18 & 1.03 & 0.85 & 0.85 & 0.86 \\
\hline Linear correlation coefficient (W-wrapping) & 0.99 & 0.98 & 0.98 & 0.97 & 0.92 & 0.92 & 0.94 & 0.94 \\
\hline
\end{tabular}

Table 4

Average, SD, COV and AAE of $V_{\text {exp }} / V_{\text {pred }}$ for the theoretical and predicted values.

\begin{tabular}{|c|c|c|c|c|c|c|c|c|}
\hline & \multicolumn{4}{|c|}{ Theoretical values } & \multicolumn{4}{|c|}{ Predicted values (GAs) } \\
\hline & $\mathrm{EC} 2+$ Fib 14 & $\mathrm{EC} 2+\mathrm{CNR}-\mathrm{DT}$ & BS $8110+$ TR55 & $\mathrm{ACl} 318-05+\mathrm{ACl} 440.2 \mathrm{R}-02$ & Fib 14 & CNR-DT & TR55 & $\mathrm{ACI} 440.2 \mathrm{R}-02$ \\
\hline Average (U-wrapping) & 1.23 & 1.32 & 1.23 & 1.23 & 1.05 & 1.05 & 0.95 & 0.95 \\
\hline SD (U-wrapping) & 0.35 & 0.36 & 0.34 & 0.29 & 0.26 & 0.19 & 0.23 & 0.22 \\
\hline COV \% (U-wrapping) & 28.20 & 27.34 & 27.82 & 23.14 & 24.78 & 18.42 & 23.80 & 22.67 \\
\hline AAE \% (U-wrapping) & 19.63 & 23.43 & 22.08 & 21.54 & 18.36 & 13.92 & 21.04 & 20.35 \\
\hline Average (W-wrapping) & 1.55 & 2.05 & 2.15 & 2.05 & 1.24 & 1.18 & 1.35 & 1.31 \\
\hline SD (W-wrapping) & 0.60 & 0.62 & 0.50 & 0.64 & 0.49 & 0.44 & 0.41 & 0.46 \\
\hline Cov \% (W-wrapping) & 39 & 30.17 & 23.16 & 39 & 39.22 & 37.54 & 30.25 & 35.29 \\
\hline AAE \% (W-wrapping) & 28.88 & 48.03 & 50.45 & 46.77 & 19.86 & 19.44 & 23.95 & 25.39 \\
\hline
\end{tabular}

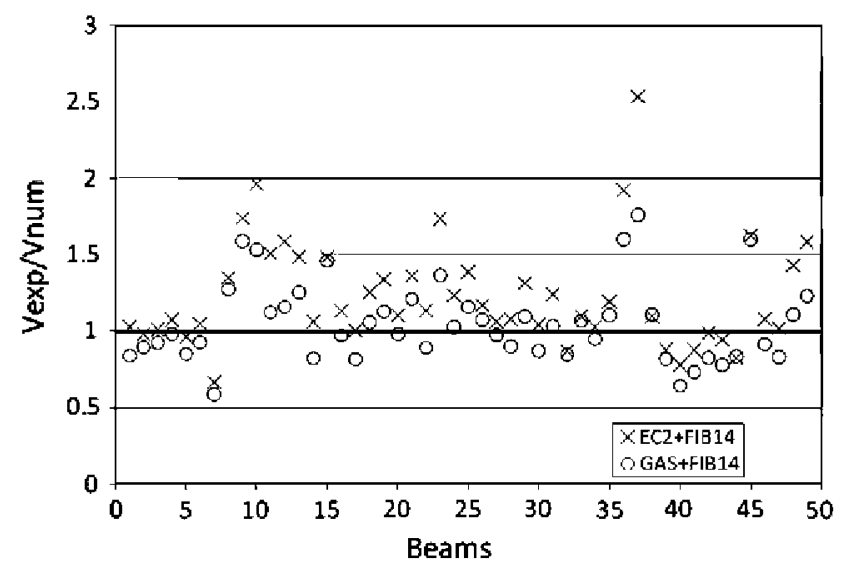

Fig. 3a. Performance of proposed shear design equations when compared with theoretical predictions (U-jacketing).

The election of the $b_{i, 0}$ coefficients is left to the designer. A value of 0.01 for all of them has also performed reasonably well.

According to Eq. (13), if there is no violation of constraints, the penalty factor $P$ is one. In the event of one or more constraints being violated, the solution is unfeasible, and the value of the penalty factor $P$ describes quantitatively the degree of violation, i.e., the amount of constraints violation present in a certain solution. The higher this amount, the nearer a certain solution is to satisfying the constraints of the problem.

\subsection{Results}

As the previous prediction of shear capacities for RC beams without FRP external reinforcement, dependent only on the parameters $C_{1}$ to $C_{5}$, was good, only the parameters $C_{6}$ and $C_{7}$ were updated when solving the constrained optimization problem of function $F_{2}^{\prime}$ (Eq. (13)). The values of the parameters $C_{6}$ and $C_{7}$ shown in Table 5 were obtained. To solve the optimization problem, the same previous GAs parameters were used although in a monobjective framework. For U-wrapped configuration, the values of $C_{6}$ and $C_{7}$ increase when compared to the previous results

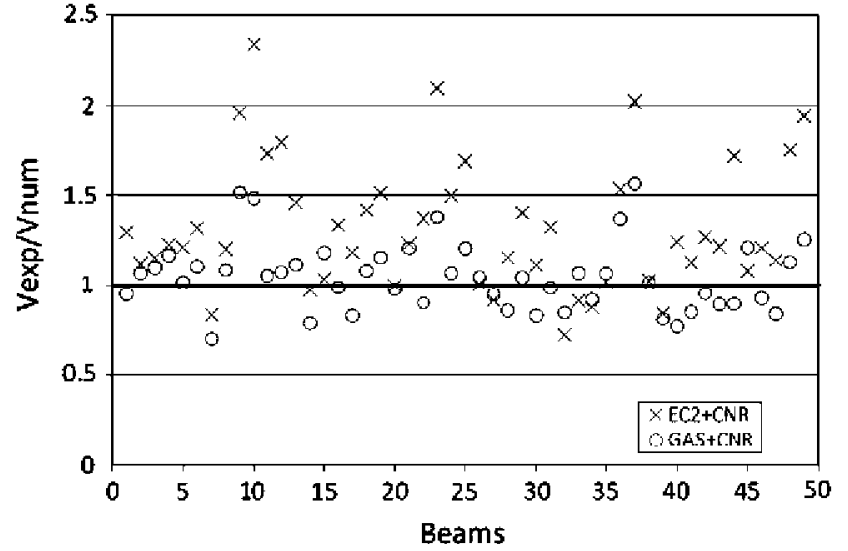

Fig. 3b. Performance of proposed shear design equations when compared with theoretical predictions (U-jacketing).

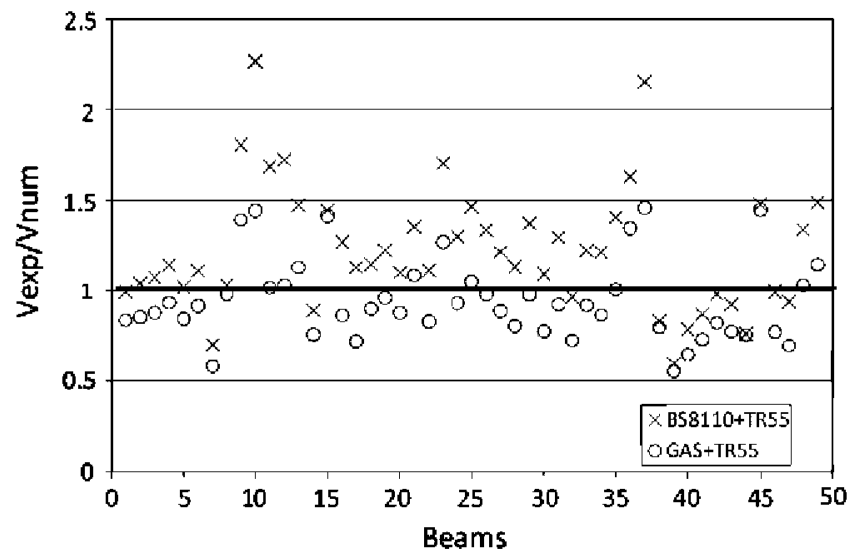

Fig. 3c. Performance of proposed shear design equations when compared with theoretical predictions (U-jacketing).

(unconservative equations) being close to one for $C_{6}$. For fully-wrapped configuration, predictions of $C_{6}$ are also close to one which means a decrease regarding the previous estimations. 


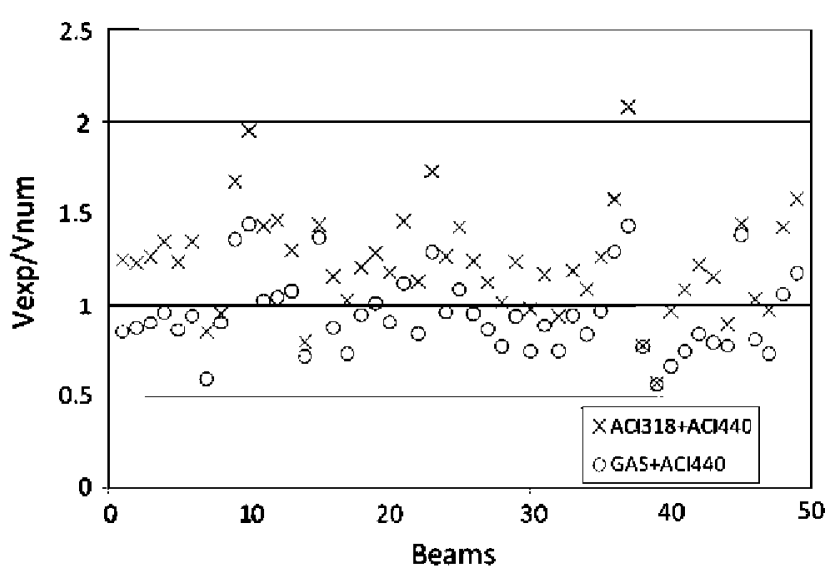

Fig. 3d. Performance of proposed shear design equations when compared with theoretical predictions (U-jacketing)

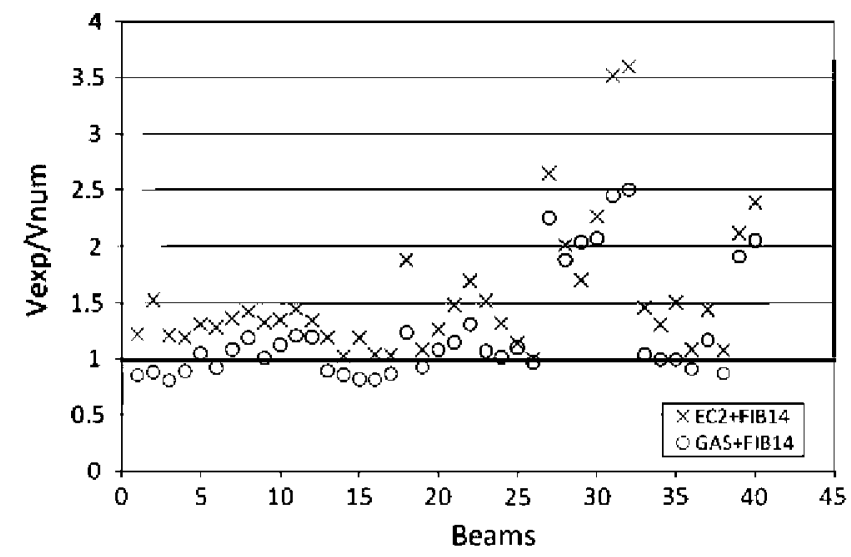

Fig. 4a. Performance of proposed shear design equations when compared with theoretical predictions (full wrapping).

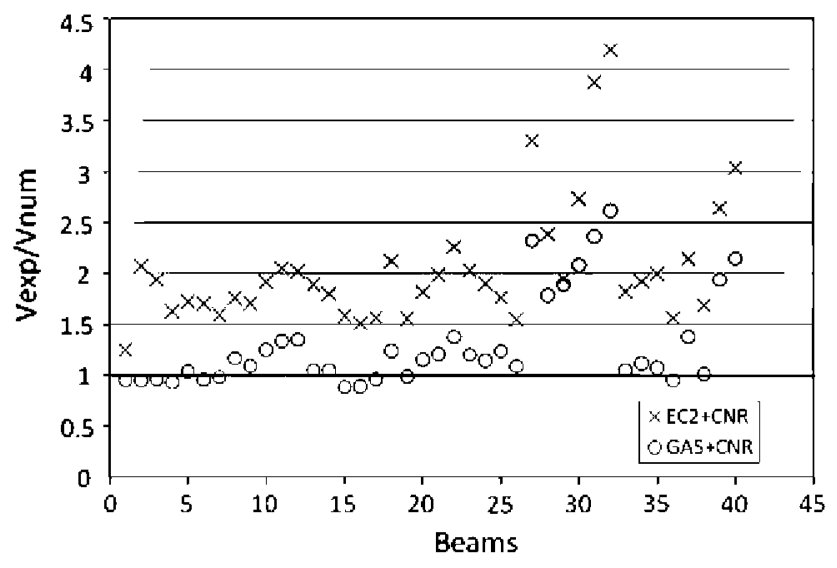

Fig. 4b. Performance of proposed shear design equations when compared with theoretical predictions (full wrapping).

In this last case, predictions for $C_{7}$ increase, but more slightly than for the U-wrapped configuration.

The performance of the new shear equations for both $U$-jacketing and full wrapping configurations is illustrated in Figs. 5 and 6, respectively, for the whole set of data. As desired, the new equations provide more conservative shear capacity predictions.

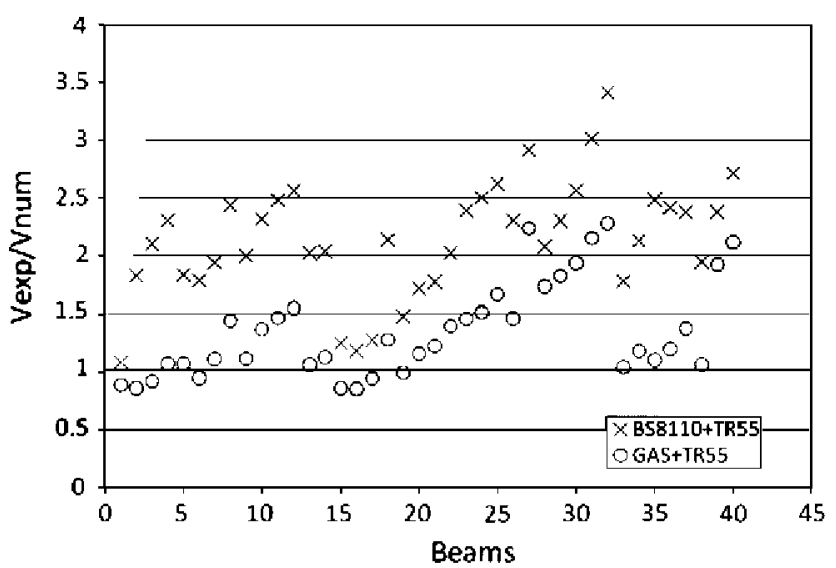

Fig. 4c. Performance of proposed shear design equations when compared with theoretical predictions (full wrapping).

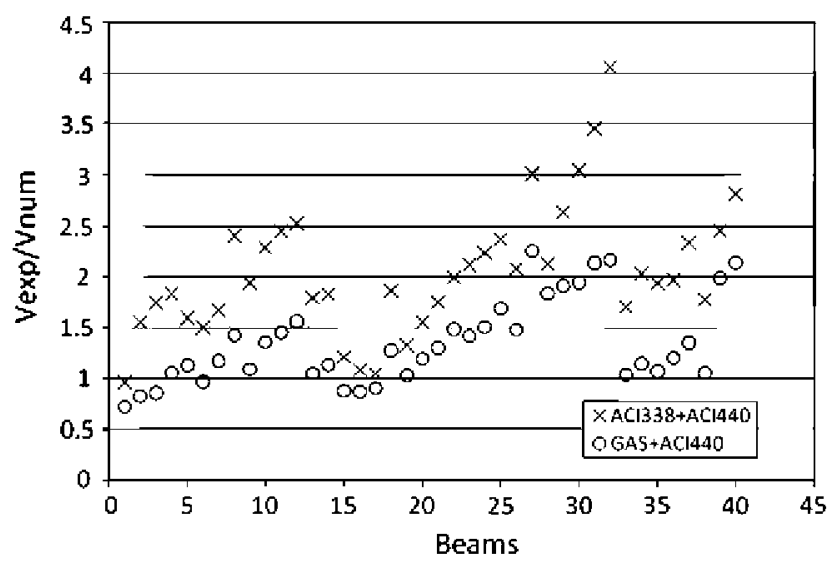

Fig. 4d. Performance of proposed shear design equations when compared with theoretical predictions (full wrapping).

Table 6 shows the average, standard deviation (SD), coefficient of variation (COV) and AAE of the ratio $V_{\text {exp }} / V_{\text {pred. }}$. for the theoretical and predicted values. When compared to Table 4 , the results show the logical tendency corresponding to more conservative equations.

\section{Conclusions}

A new method for satisfactorily estimating the shear capacity of RC beams externally shear strengthened with FRP has been proposed. Adopting the traditional truss model as a starting point to determine the total shear capacity of RC beams shear strengthened with FRP, a new more realistic approach to the subject has been proposed for the first time based on the implementation of a multiobjective optimization problem. According to this new approach the simultaneous minimization of the difference between the measured shear strength of reinforced concrete beams with and without FRP external reinforcement and its calculated values is carried out. In this way, taking into account the additive nature of the truss model, equations representing the contribution of all the terms in the total shear capacity for this kind of strengthening are obtained jointly.

With the proposed method, new shear design equations have been developed; shear strength results calculated using the proposed equations correspond well with the experimental results 
Table 5

Parameter values for the proposed equations - Conservative Equations.

\begin{tabular}{|c|c|c|c|c|c|c|c|c|}
\hline & \multicolumn{4}{|c|}{ U-wrapping } & \multicolumn{4}{|c|}{ W-wrapping } \\
\hline & $\begin{array}{l}\text { Fib } \\
14\end{array}$ & $\begin{array}{l}\text { CNR- } \\
\text { DT }\end{array}$ & TR55 & $\begin{array}{l}\mathrm{ACl} \\
440.2 \mathrm{R}-02\end{array}$ & $\begin{array}{l}\text { Fib } \\
14\end{array}$ & $\begin{array}{l}\text { CNR- } \\
\text { DT }\end{array}$ & TR55 & $\begin{array}{l}\mathrm{ACl} \\
440.2 \mathrm{R}-02\end{array}$ \\
\hline$C_{6}$ & 0.90 & 1 & 1.07 & 1.24 & 1.07 & 1.02 & 0.91 & 1.29 \\
\hline$C_{7}$ & 1.71 & 1.53 & 1.42 & 1.69 & 1.26 & 1.19 & 1.14 & 1.34 \\
\hline
\end{tabular}

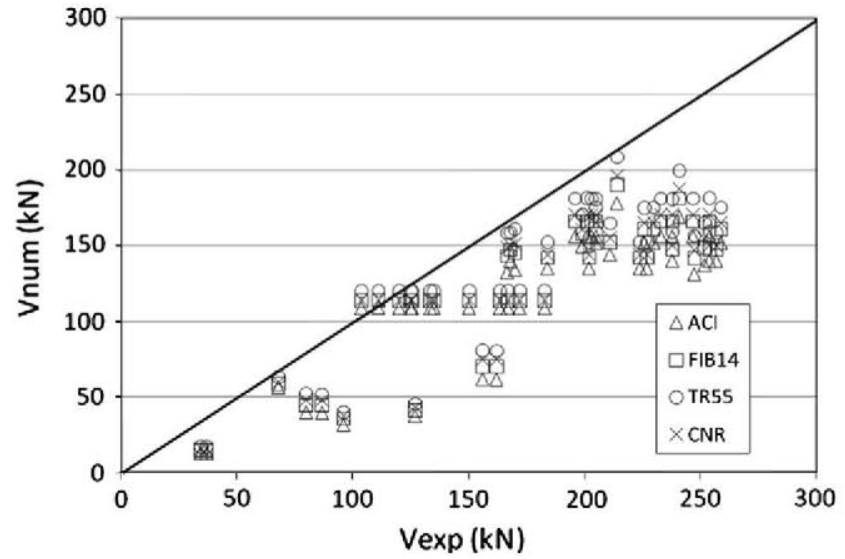

Fig. 5. Comparison of shear strength obtained by the proposed equations for Uwrapped configuration.

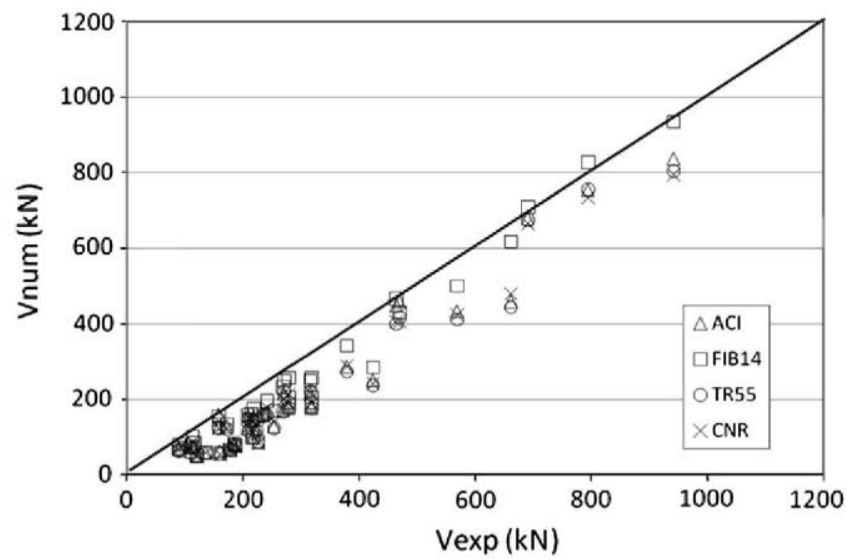

Fig. 6. Comparison of shear strength obtained by the proposed equations for fully wrapped configuration. Conservative equations.

Table 6

Average, SD, COV and AAE of $V_{\text {exp }} / V_{\text {pred }}$ for the theoretical and predicted values Conservative equations.

\begin{tabular}{lrrrc}
\hline & Fib 14 & CNR-DT & TR55 & ACI 440.2R-02 \\
\hline Average (U-wrapping) & 1.43 & 1.44 & 1.35 & 1.41 \\
SD (U-wrapping) & 0.34 & 0.37 & 0.28 & 0.32 \\
COV \% (U-wrapping) & 23.66 & 25.72 & 20.53 & 23 \\
AAE \% (U-wrapping) & 27.21 & 27.16 & 24 & 26.41 \\
Average (W-wrapping) & 1.71 & 1.79 & 1.63 & 1.60 \\
SD (W-wrapping) & 0.58 & 0.61 & 0.53 & 0.51 \\
COV \% (W-wrapping) & 33.69 & 34.02 & 32.32 & 31.99 \\
AAE \% (W-wrapping) & 36.18 & 39.17 & 32.91 & 32.33
\end{tabular}

of beams tested by several researchers. They are simple, yet more accurate than existing equations provided by current shear design guidelines and provisions.

\section{Acknowledgement}

The writers acknowledge support for the work reported in this paper from the Spanish Ministry of Science and Innovation (Project BIA2010-20234).

\section{References}

[1] Bank LC. Composites for construction: structural design with FRP materials. John Wiley and Sons; 2006.

[2] Balaguru P, Nanni A, Giancaspro J. FRP composites for reinforced and prestressed concrete structures. New York and London: Taylor and Francis; 2009

[3] Triantafillou TC, Antonopoulos CP. Design of concrete flexural members strengthened in shear with FRP. J Compos Constr 2000;4(4):198-205.

[4] Täljsten B. Strengthening concrete beams for shear with CFRP sheets. Constr Build Mater 2003;17:15-26.

[5] Carolin A, Täljsten B. Theoretical study of strengthening for increased shear bearing capacity. J Compos Constr 2005;9(6):497-506.

[6] Monti G, Liotta MA. Test and design equations for FRP-strengthening in shear. Constr Build Mater 2007;21:799-809.

[7] Perera R, Vique J, Arteaga A, De Diego A. Shear capacity of reinforced concrete members strengthened in shear with FRP by using strut-and-tie models and genetic algorithms. Compos Part B: Eng 2009;40(8):714-26.

[8] Lu XZ, Chen JF, Ye LP, Teng JG, Rotter JM. RC beams shear-strengthened with FRP: stress distributions in the FRP reinforcement. Constr Build Mater 2009;23(4):1544-54.

[9] Chaallal O, Nollet MJ, Perraton D. Strengthening of reinforced concrete beams with externally bonded fibre-reinforced-plastic plates: design guidelines for shear and flexure. Can J Civil Eng 1998;25(4):692-704.

[10] Triantafillou TC. Shear strengthening of reinforced concrete beams using epoxy-bonded FRP composites. ACl Struct J 1998;95(2):107-15.

[11] Khalifa A, Nanni A. Improving shear capacity of existing RC T-section beams using CFRP composites. Cem Concr Compos 2000;22:165-74

[12] Aprile A, Benedetti A. Coupled flexural-shear design of $\mathrm{R} / \mathrm{C}$ beams strengthened with FRP. Compos Part B: Eng 2004;35:1-25.

[13] Fib bulletin 14. Externally bonded FRP reinforcement for RC structures. Design and use of externally bonded fibre reinforced polymer reinforcement (FRP EBR) for reinforced concrete structures. Task group 9.3. FRP reinforcement for concrete structures. Lausanne, Switzerland; 2001.

[14] ACl 440.2R-02. Guide for the design and construction of externally bonded FRP systems for strengthening concrete structures. Reported by $\mathrm{ACl}$ Committee 440. American Concrete lnstitute, Farmington Hills, Michigan, USA; 2002.

[15] Concrete Society Technical Report 55. Design guidance for strengthening concrete structures using fibre composite materials. The Concrete Society, Crowthorne; 2000.

[16] CNR-DT200/2004. Guide for the design and construction of externally bonded FRP systems for strengthening existing structures. Italian National Research Council, Rome, Italy; 2004.

[17] Design Manual No. 4. Strengthening reinforced concrete structures with externally-bonded fibre reinforced polymers. Isis Canada, The Canadian Network of Centres of Excellence on Intelligent Sensing for Innovative Structures; 2001

[18] Coello CA. Recent trends in evolutionary multiobjective optimization. In: Abraham, Jain, Goldberg, editors. Evolutionary multiobjective optimization: theoretical advances and applications. London: Springer-Verlag; 2005.

[19] Lagaros ND, Papadrakakis M, Kokossalakis G. Structural optimization using evolutionary algorithms. Compos Struct 2002;80:571-89.

[20] Perera R, Varona B. Flexural and shear design of FRP plated RC structures using a genetic algorithm. J Struct Eng ASCE 2009;135(11):1418-29.

[21] Perera R, Ruiz A, Manzano C. Performance assessment of multicriteria fault identification genetic algorithm. Comp Struct 2009;87(1-2):120-7.

[22] Perera R, Ruiz A, Manzano C. An evolutionary multiobjective framework for structural damage localization and quantification. Eng Struct 2007;29:2540-50.

[23] European Committee for Standardization. Eurocode 2: design of concrete structures, Part 1: General rules and rules for buildings; 2004.

[24] American Concrete Institute. ACl building code requirements for structural concrete and commentary. ACl 318-05; 2005.

[25] EHE. Instrucción de hormigón structural. Ministry of Public Works 2008 [in Spanish].

[26] Kani MW, Huggins MW, Wittkopp RR. Kani on shear in reinforced concrete. Department of Civil Engineering, University of Toronto Press, Toronto; 1979.

[27] Goldberg D. Genetic algorithms in search, optimization and machine learning. Addison-Wesley: Reading (MA); 1989.

[28] Zitzler F., Thiele L. Multiobjective evolutionary algorithms: a comparative case study and the strength Pareto approach. IEEE Trans Evol Comput 1999;3(4):257-71

[29] Perera R, Vique J. Strut-and-tie modelling of reinforced concrete beams using genetic algorithms optimization. Constr Build Mater 2009;23:2914-25.

[30] Cladera A. Shear design of reinforced high strength concrete beams. PhD thesis published by ACHE (Spanish Concrete Association), ISBN 84-89670-2; 2003 
[31] Bhatt P, Kader MA. Prediction of shear strength of reinforced concrete beams by nonlinear finite element analysis. Comput Struct 1998;68:139-55.

[32] Liotta MA. FRP strengthening in shear: tests and design equations, PhD thesis: 2006.

[33] Alzate A, Arteaga A, De Diego A, Perera R. Shear strengthening of reinforced concrete beams using fibre reinforced polymers (FRP). Eur J Environ Civil Eng 2009;13(9): 1051-60.

[34] Perera R, Arteaga A, De Diego A. Artificial intelligence techniques for prediction of the capacity of RC beams strengthened in shear with external FRP reinforcement. Compos Struct 2010;92(5):1169-75.
[35] Perera R, Barchin M, Arteaga A, De Diego A. Prediction of the ultimate strength of reinforced concrete beams FRP-strengthened in shear using neural networks. Compos Part B: Eng 2010;41:287-98.

[36] European Committee for Standardization. Eurocode 2: Design of concrete structures, Part 1: General rules and rules for buildings; 2004

[37] BS 8110 . Structural use of concrete, Part 1: Code of practice for design and construction, British Standard; 1997.

[38] Gen M, Cheng R. A survey of penalty techniques in genetic algorithms. In: Proceeding of the sixth international symposium on robotics and manufacturing, Montpellier, France; 1996. 